\title{
Effect of Exercise Training on Glucose Tolerance, In Vivo Insulin Sensitivity, Lipid and Liproprotein Concentrations in Middle-Aged Men With Mild Hypertriglyceridemia
}

\author{
R.M. Lampman, J.T. Santinga, P.J. Savage, D.R. Bassett, C.R. Hydrick, J.D. Flora, Jr., and W.D. Block
}

\begin{abstract}
The effects of 9 weeks of aerobic exercise training with maintenance of stable body weight upon insulin sensitivity and upon glucose, lipid, and lipoprotein concentrations were studied in 10 middle-aged men with mild hypertriglyceridemia. Following training, mean maximum oxygen consumption improved from $33.5 \pm 1.9$ to $39.3 \pm 1.9 \mathrm{~mL} / \mathrm{kg} / \mathrm{min}(\overline{\mathrm{x}} \pm \mathrm{SEM})$. $(P<0.01)$. Glucose concentrations, both fasting and during oral glucose tolerance testing, remained stable but both fasting insulin concentrations and insulin responses to oral glucose decreased $(P<0.1$ and $<0.01$, respectively). In vivo insulin sensitivity improved $25 \pm 6.1 \%(P<0.01)$ following training. Exercise training resulted in decreases in fasting serum triglyceride concentrations from $203 \pm 12.6$ to $126 \pm 9.0 \mathrm{mg} / \mathrm{dL}(P<0.01)$, primarily as a result of the reduction in VLDL-triglycerides $(P<0.01)$. The magnitude in percentage decrease of VLDL-triglycerides was found to be significantly correlated $(r=0.71, P<0.05)$ with the magnitude in percent increase in max $\mathrm{VO}_{2}$. Serum cholesterol levels declined from $211 \pm 8.9$ to $193 \pm 11.9 \mathrm{mg} / \mathrm{dL}(P<0.01)$, and the ratio of HDL-cholesterol to total cholesterol was improved. This study demonstrates that exercise training at a level of intensity feasible for many middle-aged men has beneficial effects on several factors that have been essociated with an increased risk of cardiovascular disease.
\end{abstract}

(1) 1985 by Grune \& Stratton, Inc.

$\mathbf{P}$

REVIOUS WORK from our laboratory has shown that physical training of middle-aged men with hyperlipidemia significantly lowers plasma triglyceride concentrations, ${ }^{1-3}$ and reduces fasting insulin levels, ${ }^{2}$ a simple measurement that has been shown to correlate with in vivo insulin sensitivity. ${ }^{4}$ Elevated concentrations of plasma triglycerides have been associated with abnormalities in glucose tolerance, increased plasma insulin concentrations, and in vivo resistance to insulin action. $^{5-7}$ In addition, since increased triglyceride levels frequently are associated with increased low density lipoprotein (LDL) levels and reduced high density lipoprotein (HDL) cholesterol concentrations, hypertriglyceridemic patients are often at increased risk for the development of coronary heart disease ${ }^{8-t 0}$ Since physical conditioning has major effects upon the metabolism of glucose and other metabolic fuels, " this study was conducted to assess the effects of moderate dynamic exercise training while weight was held steady upon glucose tolerance, insulin response to oral glucose, and in vivo insulin resistance, as well as upon levels of cholesterol, triglyceride, and lipoprotein fractions.

\section{MATERIALS AND METHODS}

\section{Subjects}

Ten sedentary, male subjects, aged 34 to 58 years $(\overline{\mathrm{x}} \pm \mathrm{SD} ; 44.5 \pm$ 2.61 years), with $\bar{x} \pm$ SD height of $179.3 \pm 2.6 \mathrm{~cm}$ were selected from University of Michigan staff members known to have mild endogenous hypertriglyceridemia, defined as having fasting plasma triglyceride levels in excess of $150 \mathrm{mg} / \mathrm{dL}$, and plasma cholesterol levels less than $260 \mathrm{mg} / \mathrm{dL}$. All subjects gave written informed consent prior to participation in the study. None had acute or chronic infectious disease, or evidence of cardiovascular, respiratory, hepatic, or renal disease. All denied taking any medication known to alter glucose or lipid metabolism in the weeks preceding or during the time of the study.

\section{Experimental Protocol \\ General}

Upon entry into the study, a baseline fasting blood sample was obtained for measurement of glucose, insulin, lipid, and lipoprotein concentrations. A treadmill stress test, an oral glucose tolerance test, and an insulin sensitivity test were performed. Subjects then were started on a 9-week exercise program. ${ }^{3}$ The intensity of exercise prescribed was based upon the initial treadmill exercise test. Subjects returned to the hospital at three-week intervals throughout the study for weighing, dietary consultation, and measurement of fasting glucose, insulin, lipid, and lipoprotein concentrations. After completion of the 9-week program, the initial series of studies was repeated.

\section{Biochemical Measurements}

Blood for biochemical determinations was drawn into test tubes containing EDTA, the plasma immediately separated, and aliquots obtained for determinations of glucose, ${ }^{12,13}$ insulin, ${ }^{14,15}$ and lipid ${ }^{16-18}$ concentrations. Chylomicrons were removed ${ }^{16}$ from samples prior to lipoprotein determinations and the very low density lipoprotein (VLDL) then were separated by ultracentrifugation. In the infranate, the HDL and LDL were separated by precipitation of the latter by the heparin-manganese chloride method. ${ }^{17}$ Plasma chylomicrons, VLDL, total HDL + LDL, and HDL fractions subsequently were

From the Divisions of Cardiology, Endocrinology and Metabolism. and Hypertension. Department of Internal Medicine: the Clinical Research Center; and the Departments of Biostatistics and Community Health Programs, University of Michigan, Ann Arbor.

Supported in part by grants from the National Institutes of Health, General Clinical Research Center, NIH \#5-MO1RR00042, and the National Institute of Arthritis, Diabetes, Digestive and Kidney Diseases, Diabetes Research and Training Center grant \#P60-AM20572.

Address reprint requests to Richard M. Lampman, PhD, Division of Cardiology, Department of Internal Medicine. University of Michigan Medical Center, 1405 East Ann Street, Ann Arbor, MI 48109.

(C) 1985 by Grune \& Stratton, Inc. 0026-0495/85/3403-0001\$3.00/0 
analyzed for cholesterol and triglyceride concentrations. ${ }^{18} \mathrm{LDL}$ fraction values were obtained by subtraction of HDL levels from those of the total fraction of HDL + LDL.

\section{Dietary Measures}

Initially, a history of each subject's usual food intake was obtained by a dietitian using the dietary interview method. The dietitian then instructed each subject to continue his typical eating patterns and to maintain wcight by slightly incrcasing $(150-170 \mathrm{Kcal} / \mathrm{d})$ his total calorie intake to compensate for the additional caloric expenditure due to exercise training. Success was monitored by having the subjects keep three-day food diaries that were reviewed at threeweek intervals throughout the study. Data from these records were subsequently analyzed to assess the subject's caloric consumption, food composition, and compliance to dietary protocol. ${ }^{19}$

\section{Progressive Treadmill Exercise Test and Exercise Training Prescription}

The cardiovascular response during acute exercise of all subjects was measured on a treadmill as previously described. ${ }^{1}$ Each subject was encouraged to walk to a termination point of subjective exhaustion. During the test, a bipolar $\mathrm{C}_{\mathrm{M}}$, electrocardiogram was monitored, blood pressures were obtained by auscultation, and maximal oxygen uptake ( $\mathrm{Max} \mathrm{V}_{2}$ ) was measured by indirect spirometry. ${ }^{20}$ The data from the initial test were used to prescribe the desired work intensity (effort needed to attain $85 \%$ of maximal heart rate for each subject by jogging). Three 30-40-minute exercise sessions were scheduled each week over the 9-week period as previously described. ${ }^{3}$ With this training protocol, the subjects averaged between 9 to 12 miles of jogging per week.

\section{Oral Glucose Tolerance Test (OGTT)}

Subjects underwent a 3-hour oral glucose tolerance test (glucose $=1.75 \mathrm{gm} / \mathrm{kg}$ ideal body weight) after an overnight fast. In preparation for the test, all were instructed by the dietitian to follow an isocaloric diet with $50 \%$ of calories from carbohydrates for three days. Subjects were classified as having normal glucose tolerance on the basis of criteria from the National Diabetes Data Group. ${ }^{21}$

\section{Insulin Sensitivity Test}

Forty-eight hours following the OGTT and while still continuing on the isocaloric $50 \%$ carbohydrate diet, each subject underwent a test of in vivo insulin sensitivity according to the procedure described by Shen et al. ${ }^{22}$ This involves a continuous intravenous infusion of epinephrine $(6 \mu \mathrm{g} / \mathrm{min})$, propranolol $(0.08 \mathrm{mg} / \mathrm{min})$, glucose $(6$ $\mathrm{mg} / \mathrm{kg} / \mathrm{min})$, and insulin $(80 \mathrm{mU} / \mathrm{min}$ ) for a period of 150 minutes, using a constant infusion pump. The plasma concentrations of insulin and glucose were measured every 10 minutes from 90 to 150 minutes on samples obtained from an indwelling needle placed in the opposite forearm. Since this technique produces similar insulin concentrations in all subjects, the average level of glucose maintained can be taken as an index of insulin sensitivity. ${ }^{22}$ Before, during, and for 15 minutes after this test, blood pressures were measured frequently and heart rate responses of the patients were monitored constantly.

\section{Intervention and Final Assessment}

After initial assessment, subjects initiated their exercise program and returned to the hospital at three-week intervals for interim and final assessments. At the three- and six-week visits, a blood sample was drawn (after a 12-hour fast and 48 hours after the last period of exercise) for determinations of glucose, insulin, and lipid concentrations. Body weight was measured to assure that stable weights were being maintained and, if necessary, the dietitian made minor modifications in the diet plan. At the end of the 9 -week intervention period, the initial series of tests was repeated.

\section{Statistical Methods}

Statistical analyses were performed using standard techniques. ${ }^{23}$ Students' paired t-tests were employed on data obtained from the treadmill exercise and insulin sensitivity tests, while glucose and insulin values obtained during the oral glucose tolerance tests and fasting glucose, insulin, lipid, and lipoprotein concentrations were analyzed using a one-way repeated measures analysis of variance (ANOVA). ${ }^{24,25}$

\section{RESULTS}

\section{Measurement of Physical Fitness Level}

Results (mean \pm SEM) of treadmill exercise testing to maximum tolerance are shown in Table 1. After the 9-week physical training program, the subjects increased both their aerobic capacities $(33.5 \pm 1.9$ to $39.3 \pm 1.9 \mathrm{~mL} / \mathrm{kg} / \mathrm{min}, P<0.01)$ and total time walking on the treadmill prior to subjective exhaustion $(22 \pm 1.6$ to $27 \pm 1.7$ minutes, $P<0.01)$, indicating an improved level of physical fitness. No change was found between baseline and final maximum exercise heart rate, systolic blood pressure, and rate pressure "product values, indicating that equal cardiovascular stress was obtained during both stress tests.

\section{Effects of Physical Training on Body Weight and Dietary Compliance}

Stable body weights were maintained during the exercise training program $(82.3 \pm 4.3 \mathrm{~kg}$ initial, $81.2 \pm$ 4.1 final, NS). Mean \pm SD body mass index [BMI = weight $(\mathrm{kg}) /$ height $\left.(\mathrm{M})^{2}\right]^{26}$ at baseline was $25.5 \pm 1.0$. Idcal BMI was considered to be $22.5 \mathrm{~kg} / \mathrm{M}^{2}$. Relative body weight was calculated by dividing the subject's BMI by $22.5 \mathrm{~kg} / \mathrm{M}^{2}$. BMI values greater than $20 \%$ above ideal are considered obese ${ }^{27}$; as a group, our subjects were not obsese by this criterion. Subjects initially reported diets containing $(\bar{x} \pm S D) 2487.6 \pm$ $173.7 \mathrm{Kcal}$ and having compositional mean values of $17.5 \%$ protein, $40.5 \%$ fat, $41 \%$ carbohydrate, and $1.0 \%$

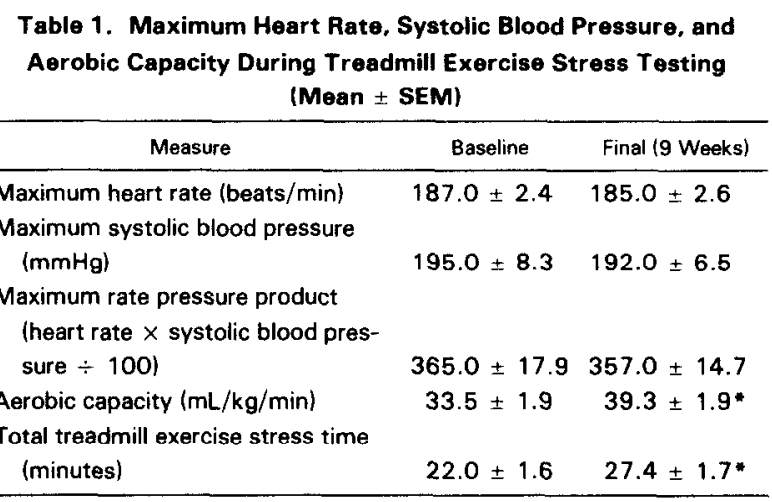

* Significantly $(P<0.01)$ different from baseline value by paired t-test. 


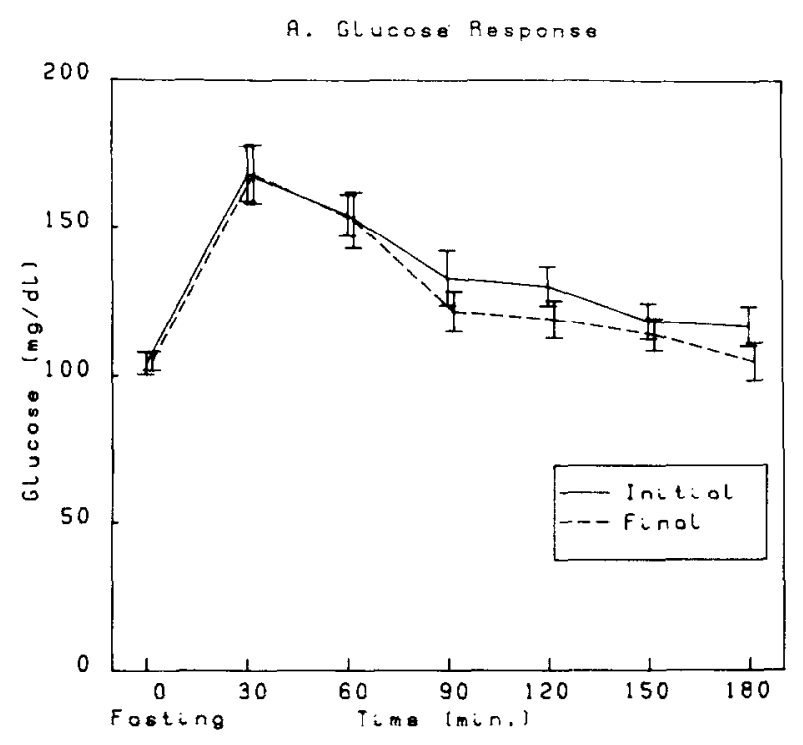

B. Insulin Response

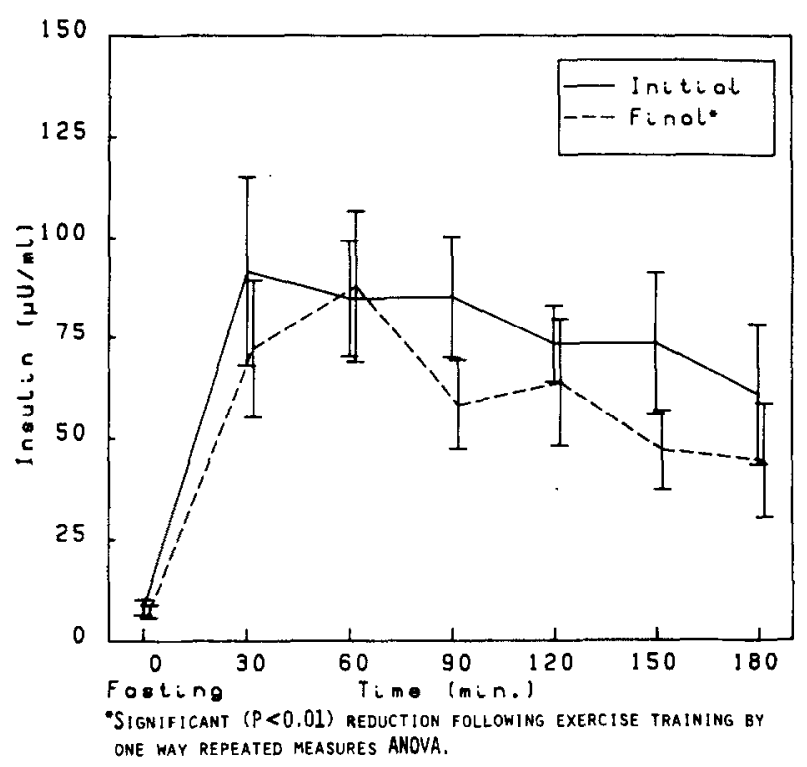

Fig 1. Glucose and insulin concentrations during initial and final oral glucose tolerance test (Mean \pm SEM).

ethanol. By dietary history, exercise energy expenditure was accompanied by a mean increase of 166 $\mathrm{Kcal} / \mathrm{d}$. No significant differences in dietary composition were observed throughout the study (data not presented).

\section{Three-Hour Oral Glucose Tolerance Test}

Plasma glucose and insulin responses for the oral glucose tolerance tests, both before and after physical training, are shown in Figure 1. Little change was observed in glucose concentrations between initial and final tests (NS). In contrast, a significant $(P<0.01)$ reduction was found in plasma insulin concentrations during the final oral glucose tolerance test.

\section{Effects of Exercise Training on Metabolic Variables Glucose and Insulin}

Fasting plasma glucose and insulin concentrations, determined initially and at 3,6, and 9 weeks, are shown in Table 2. No significant alteration was found in fasting glucose concentrations during exercise training. During the period of exercise training, however, fasting insulin concentrations declined somewhat $(P=$ 0.09). A modest correlation of 0.44 (Spearman's rho), $P=0.15$, was found between initial fasting plasma insulin and triglyceride concentrations. A weak association was found between fasting triglyceride levels and insulin levels ( $r=0.14, \mathrm{NS}$ ) following an oral glucose challenge.

\section{Lipids and Lipoproteins}

Fasting plasma cholesterol, HDL-cholesterol and LDL-cholesterol, triglyceride, and VLDL-triglyceride concentrations and the ratio of $\mathrm{HDL}$-cholesterol to total cholesterol, expressed as a \% of total cholesterol, are shown in Table 3. Both total cholesterol and triglyceride concentrations decreased $(P<0.01)$ during the training program. A decrease in VLDL-cholesterol concentrations accounted for the majority of change seen in total cholesterol concentrations $(P<$ $0.01)$. VLDL-triglyceride concentrations declined $(P<0.01)$, and these changes correlated with changes in total triglyceride levels $(\mathrm{r}=0.78 ; P<0.01)$. The major reduction in both total triglycerides and VLDLtriglycerides was observed at the end of the six weeks, and these decreased levels persisted to the final study period (Table 3). The magnitude in percent decrease of VLDL-triglycerides was found to be significantly correlated $(\mathrm{r}=0.71, P<0.05)$ with the magnitude in percent increase in maximum oxygen consumption $\left(\max \dot{\mathrm{VO}}_{2}\right.$ ). While HDL-cholesterol concentrations were initially low at $37.6 \pm 3.5$, the exercise intervention resulted in only a slight increase of $2.5 \mathrm{mg} / \mathrm{dL}$

Table 2. Fasting Plasma Glucose and Insulin Concentrations (Mean \pm SEM)

\begin{tabular}{|c|c|c|c|c|}
\hline \multirow[b]{2}{*}{ Measure } & \multicolumn{4}{|c|}{ Time Period } \\
\hline & Initial & 3 Weeks & 6 Weeks & $\begin{array}{c}\text { Final } \\
\text { (9 Woeks) }\end{array}$ \\
\hline Glucose (mg/dL) & $106.7 \pm 2.7$ & $107.1 \pm 2.6$ & $103.2 \pm 1.9$ & $102.6 \pm 3.4$ \\
\hline Insulin $(\mu \mathrm{U} / \mathrm{mL})^{*}$ & $13.2 \pm 1.3$ & $9.9 \pm 1.1$ & $10.3 \pm 1.7$ & $10.2 \pm 1.2$ \\
\hline
\end{tabular}

* Reduction with respect to time by one-way repeated measures ANOVA $(P<0.1)$. 
Table 3. Lipid and Lipoprotein Concentrations (Mean \pm SEM)

\begin{tabular}{|c|c|c|c|c|}
\hline \multirow[b]{2}{*}{$\begin{array}{l}\text { Lipid and } \\
\text { Lipoprotein }\end{array}$} & \multicolumn{4}{|c|}{ Time Period } \\
\hline & Initial & 3 Weoks & 6 Weoks & $\begin{array}{c}\text { Final } \\
\text { (9 Woeks) }\end{array}$ \\
\hline Cholesterol * $(\mathrm{mg} / \mathrm{dL})$ & $210.9 \pm 8.9$ & $180.7 \pm 9.4$ & $189.7 \pm 8.3$ & $193.2 \pm 11.9$ \\
\hline \multicolumn{5}{|l|}{ HDL-Cholesterol } \\
\hline$(\mathrm{mg} / \mathrm{dL})$ & $37.6 \pm 3.5$ & $35.5 \pm 2.9$ & $37.0 \pm 2.8$ & $40.1 \pm 4.1$ \\
\hline \multicolumn{5}{|l|}{ LDL-Cholesterol } \\
\hline (mg/dL) & $125.5 \pm 9.0$ & $114.3 \pm 9.1$ & $125.5 \pm 7.6$ & $125.9 \pm 11.0$ \\
\hline \multicolumn{5}{|l|}{ HDL-Cholesterol/total } \\
\hline \multicolumn{5}{|l|}{ cholesterol $x$} \\
\hline $100(\%)$ & $17.9 \pm 1.5$ & $20.2 \pm 1.8$ & $19.6 \pm 1.5$ & $21.1 \pm 2.2$ \\
\hline Triglyceridest (mg/dL) & $202.8 \pm 12.6$ & $133.8 \pm 13.6$ & $128.1 \S \pm 9.7$ & $125.7 \ddagger \pm 10.4$ \\
\hline \multicolumn{5}{|l|}{ VLDL-Triglycerides $\dagger$} \\
\hline$(\mathrm{mg} / \mathrm{dL})$ & $159.9 \pm 10.6$ & $99.5 \pm 13.2$ & $73.4 \S \pm 9.9$ & $87.9 \S \pm 9.0$ \\
\hline
\end{tabular}

- Significant $(P<0.05)$ reduction during time of study by one-way repeated measures ANOVA.

†Significant $(P<0.01)$ reduction during time of study by one-way repeated measures ANOVA.

$\ddagger$ Significantly different from initial value $(P<0.05)$.

\$Significantly different from initial value $(P<0.01)$

(NS). The change in HDL-cholesterol/total cholesterol ratio, however, reached levels of borderline significance $(P=0.06)$.

Correlation analysis showed only a minimal inverse association between initial total triglyceride and HDLcholesterol concentrations (Spearman's rho $=-0.25$; NS).

\section{Plasma Glucose and Insulin Values During the Insulin Sensitivity Test}

In vivo insulin resistance, as measured by mean glucose concentrations during the 90-150-minutc period of the insulin sensitivity test, is shown in Figure 2. Following physical training, steady state plasma glucose levels decreased from $140 \pm 11.7$ to $104 \pm 11.3$ $\mathrm{mg} / \mathrm{dL}(P<0.01)$, indicating improved insulin

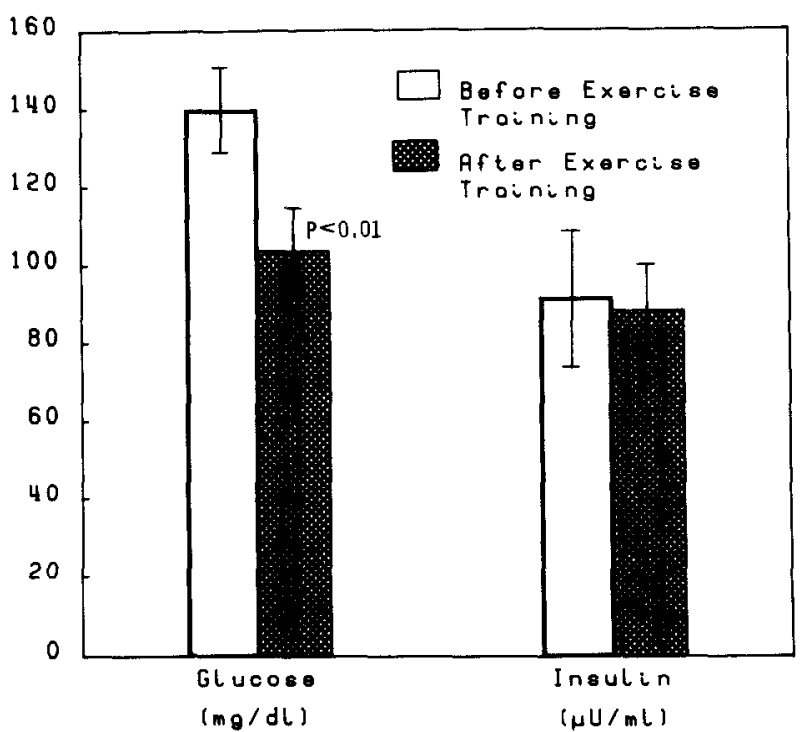

Fig 2. Initial and final plasma glucose and insulin levels during the in vivo insulin sensitivity tests (Mean \pm SEM). mediated glucose uptake. The steady state plasma insulin values did not change significantly $(91.4 \pm 16.5$ $\mu \mathrm{U} / \mathrm{mL}$ and $88.1 \pm 12.2 \mu \mathrm{U} / \mathrm{mL}$ at baseline and final studies, respectively), indicating that the change in glucose levels was related to a change in tissue sensitivity to insulin.

No significant association was found in this study between insulin sensitivity and physical fitness levels as estimated by measurements of $\max \mathrm{VO}_{2}$. At baseline measurements, the correlation between insulin sensitivity and $\max \dot{\mathrm{VO}}_{2}$ was $0.57(0.05<P<0.1)$. Following exercise training, this correlation was 0.36 , NS. When baseline and final values were considered together, neither the absolute nor the percentage change in $\max \mathrm{V}_{2}$ was correlated with the absolute or percentage change in insulin sensitivity $(r=0.22$ and 0.06 , NS, respectively). No significant association was found between absolute or percent change in $\max \mathrm{V}_{2}$ and other metabolic variables with the exception (see above) of VLDL-triglycerides and $\max \mathrm{VO}_{2}$.

\section{DISCUSSION}

Results from this study are consistent with previous reports ${ }^{1-3}$ from our laboratory showing that an exercise training program prescribed for relatively sedentary, mildly hyperlipidemic middle-aged men is a potent intervention for lowering plasma triglyceride concentrations. This training program involved an exercise effort of $85 \%$ maximum heart rate, with an average of between 9 to 12 miles of walking-jogging per week by the end of the 9-week study, and resulted in an increase in aerobic capacity of $17 \%$ at conclusion of the exercise program.

In some reports, a link has been suggested between increased peripheral tissue insulin resistance and endogenous hypertriglyceridemia. ${ }^{5-7}$ To investigate 
this further, oral glucose tolerance tests and insulin sensitivity tests were administered at baseline and after the exercise program in order to provide an assessment of changes in in vivo resistance to both endogenous and exogenous insulin, respectively.

Insulin levels during the final oral glucose tolerance test were significantly decreased, and fasting plasma insulin measurements made over the 9-week training period tended to decline even though no significant changes were observed in oral glucose tolerance or in fasting glucose levels following exercise training. These interesting findings suggest enhanced sensitivity to endogenous insulin following exercise training. Similar results have been reported for patients of normal weight with Type II diabetes undergoing an exercise program. ${ }^{28}$ However, these findings are not universal, since subjects having fasting hyperglycemia ${ }^{29}$ or extreme obesity ${ }^{30}$ do not show similar reduced insulin levels following oral glucose challenge. These conflicting findings suggest that exercise training may have differing effects on circulating insulin and insulin response to oral glucose tolerance, dependent on the degree of glucose impairment and/or obesity.

An important result of this study was that exercise training, without weight loss, resulted in a significant improvement in in vivo insulin sensitivity of these hypertriglyceridemic subjects as assessed by the insulin sensitivity test of Shen et al. ${ }^{22}$ Few studies exist that have directly measured in man the effect of exercise training on insulin resistance, and none until the current study have addressed this problem in hypertriglyceridemic patients. Results from one study showed improved insulin sensitivity in young, nondiabetic, athletic subjects participating in a very strenuous physical training program. ${ }^{31}$ Wallberg-Henriksson et $\mathrm{al}^{32}$ reported similar findings in young, nonobese Type I diabetics undergoing a more moderate training program. These reports, together with findings from the current study, suggested that exercise training is of benefit in altering insulin resistance, and may especially be helpful if hypertriglyceridemia is present.

Both Rosenthal et $\mathrm{al}^{33}$ and Bogardus et al ${ }^{34}$ recently have reported significant associations between measurements of insulin sensitivity using the euglycemic clamp technique ${ }^{35}$ and estimates of fitness level as measured by $\max \dot{V}_{2} \mathrm{O}_{2}$ cross-sectional studies. Since Greenfield et $a 1^{36}$ reported a high correlation between insulin sensitivity measurements during the steady state plasma glucose test and the euglycemic clamp technique $(\mathrm{r}=0.93, P<0.001)$, we looked for a relationship between measures of insulin sensitivity and $\max \mathrm{VO}_{2}$ in our subjects. Although the correlation between these variables at baseline were similar to that reported in the above studies, the correlation declined following exercise training and we found no evidence of an association between changes in insulin sensitivity and in max $\mathrm{VO}_{2}$ that occurred during our study.

Our data are consistent with those of Reaven et al, ${ }^{37}$ showing that mild endogenous hypertriglyceridemia and some degree of insulin resistance can occur even in subjects who are not obese. Weight and diet were successfully maintained in the current study, so as to not have these factors as confounding variables. As found in this study and in previous reports from our laboratory, ${ }^{1-3}$ exercise training alone is a potent factor in attenuating hypertriglyceridemia; the present report shows that the major reductions occur in the VLDLtriglyceride levels.

It is conceivable that the moderate degree of insulin resistance displayed by these hyperlipidemic individuals resulted in increased hepatic production of VLDLtriglyceride..$^{5-7}$ Our results show that no simple relationship existed between insulin responses to oral glucose and basal triglyceride levels, or between insulin responses to oral glucose and basal triglyceride levels, or between insulin resistance and plasma triglyceride levels. This negative finding is probably due to the somewhat narrow distribution of plasma triglyceride levels seen in our patient population, and suggests that our selection criteria of patients exhibiting only slight impairments in glucose tolerance represented just a small segment in the continuous spectrum of endogenous hypertriglyceridemia. The mild hypertriglyceridemia seen in our patients may have been sustained and possibly even caused by tissue insulin resistance. Our finding of reduced fasting total triglyceride and VLDL-triglyceride levels in combination with improved insulin sensitivity and reduced insulin levels following exercise training supports this contention. Exercise training, having significantly reduced insulin resistance and decreased insulin levels, should lead to a decreased hepatic VLDL-triglyceride production, and decreased plasma VLDL-triglyceride concentrations.

Hypertriglyceridemia may also be associated with diminished clearance, ${ }^{38.39} \mathrm{or}$, in some subjects, a combination of both increased synthesis and reduced clearance of VLDL-triglycerides. ${ }^{40} \mathrm{Our}$ findings of reduced insulin response to oral glucose without deterioration of glucose tolerance following training suggest enhanced insulin action. This factor may have improved the ability of insulin to regulate the delipidation of VLDL-triglyceride; abnormalities in this process may be associated with hypertriglyceridemia. ${ }^{41}$ Consistent with this reasoning is the report of Nikkilä et $\mathrm{a}^{42}$ showing increased lipoprotein lipase activity in adipose tissue and skeletal muscle of athletes, a finding that they consider could account for the increased turnover rates of triglyceride-rich lipoproteins. Our 
findings in this study are consistent with this view, since the major lipoprotein fraction influence by exercise training was the very low density lipoproteins.

Results from the current study indicate that hypertriglyceridemic subjects have decreased concentrations of high density lipoprotein cholesterol, and confirm earlier work indicating an inverse association between high density lipoprotein cholesterol and total triglyceride concentrations. ${ }^{8}$ Although cholesterol concentrations significantly decreased with training, high density lipoprotein cholesterol levels only slightly increased. Since a threshold of approximately 8-10 miles of running per week for an extended training period appears necessary to beneficially alter low and high density lipoprotein concentrations, ${ }^{43,44}$ a physical training program longer than 9 weeks may prove even more beneficial for middle-aged men with hyperlipidemia.

This study demonstrates that moderate intensity exercise training that succeeded in significantly increasing aerobic capacity results in enhanced insulin-mediated glucose disposal, a marked decrease in serum triglyceride and cholesterol concentrations, lower insulin response to oral glucose without change in glucose tolerance, and diminished fasting insulin levels in middle-aged subjects with mild endogenous hypertriglyceridemia. This exercise training regime with maintenance of stable weight was also effective in reducing very low density lipoprotein cholesterol and triglyceride concentrations, and favorably altered the ratio of high density lipoprotein cholesterol to total cholesterol. Although control studies would be necessary to fully quantify the changes attributed to exercise training alone, the numcrous changes obscrved in this study strongly suggest that exercise training is an effective means for the clinical management of patients with endogenous hypertriglyceridemia, and may be a valuable adjunctive therapy to dietary management, especially where a reduction in weight is desirable.

\section{ACKNOWLEDGMENT}

We acknowledge our debt to Donald A. Hook for technical assistance, to Ken E. Guire and Barbara N. Campaigne for statistical assistance, and to Betty A. Plunkett for manuscript typing.

\section{REFERENCES}

1. Lampman RM, Santinga JT, Hodge MF, et al: Comparative effects of physical training and diet in normalizing serum lipids in men with type IV hyperlipoproteinemia. Circulation 55:652-659, 1977

2. Lampman RM, Santinga JT, Bassett DR, et al: Effectiveness of unsupervised and supervised high intensity physical training in normalizing serum lipids in men with type IV hyperlipoproteinemia. Circulation 57:172-180, 1978

3. Lampman RM, Santinga JT, Bassett DR, et al: Type IV hyperlipoproteinemia: Effects of a caloric restricted type IV diet versus physical training plus isocaloric type IV diet. Am J Clin Nutr 33:1233-1234, 1980

4. Nagulesparan M, Savage PJ, Unger RH, et al: A simplified method using somatostatin for the assessment of in vivo insulin resistance over a range of obesity. Diabetes 28:980-983, 1979

5. Reaven GM, Lerner RL, Stern MP, et al: Role of insulin in endogenous hypertriglyceridemia. J Clin Invest 46:1756-1767, 1967

6. Olefsky JM, Farquhar JW, Reaven GM: Reappraisal of the role of insulin in hypertriglyceridemia. Am J Med 57:551-560, 1974

7. Tobey TA, Greenfield M, Kraemer F, et al: Relationship between insulin resistance, insulin secretion, very low density lipoprotein kinetics, and plasma triglyceride levels in normotriglyceridemia man. Metabolism 30:164-171, 1981

8. Schaefer EJ, Levy RI, Anderson DW, et al: Plasma-triglycerides in regulation of H.D.L. cholesterol levels. Lancet 2:391-393, 1978

9. Castelli WP, Doyle JT, Gordon T, et al: HDL cholesterol and other lipids in coronary heart disease: The Cooperative Lipoprotein Phenotyping Study. Circulation 55:767-772, 1977

10. Miller NE, F $\phi r d e$ OH, Thelle DS, et al: The Troms $\phi$ heart study: high-density lipoprotein and coronary heart-disease; a prospective case-control study. Lancet 1:965-967, 1977

11. Felig P, Wahren J: Fuel homeostasis in exercise. N Eng1 J Med 20:1078-1084, 1975
12. Slein MW: Methods of Enzymatic Analysis. New York, Academic Press, 1963, p 117

13. Bondar RJL, Mean D: Evaluation of glucose-6-phosphate dehydrogenase from leuconostocmesenteroids in the hexokinase method for determining glucose in serum. Clin Chem 20:586-590, 1974

14. Soeldner JS, Sloane D: Critical variables in the radiimmunoassay of serum insulin using the double antibody technique. Diabetes 14:771-779, 1965

15. Morgan CR, Lazarow A: Immunoassay of insulin: Two antibody systems. Diabetes 12:115-126, 1963

16. Hatch FT: Practical methods for plasma lipoprotein analysis. Adv Lipid Res 6:1-68, 1968

17. Warnick GR, Albers JJ: A comprehensive evaluation of the heparin-manganese precipitation procedure for estimating high density lipoprotein cholesterol. J Lipid Res 19:65-76, 1978

18. Lipid Research Clinics Manual of Laboratory Operations (Vol 1). Lipid and Lipoprotein Analysis. HEW No. NIH 75-628. Washington, D.C., US Government Printing Office, 1974

19. Nichols AB, Ravenscroft C, Lamphier DE, et al: Daily nutritional intake and serum lipid levels. The Tecumseh Study. Am J Clin Nutr 29:1384-1392, 1976

20. Consolazio CF, Johnson RE, Pecora LJ: Physiological measurements of metabolic function in man. New York, McGraw-Hill, 1963

21. National Diabetes Data Group. Classification and Diagnosis of Diabetes Mellitus and Other Categories of Glucose Intolerance. Diabetes 28:1039-1057, 1979

22. Shen SW, Reaven GM, Farquhar JW: Comparison of impedance to insulin-mediated glucose uptake in normal subjects and in subjects with latent diabetes. J Clin Invest 49:2151-2160, 1970

23. Fox DJ, Guire KE: Documentation for MIDAS. Statistical Research Laboratory of the University of Michigan, 1973

24. Morrison DF: Multivariate Statistical Methods. New York, McGraw-Hill, 1967 
25. Brown MB, Engelman L, Frane JW, et al: BMDP Statistical Software 1981. Los Angeles, University of California Press, 1981

26. Keys A, Fidanza F, Karvonen MJ, et al: Indices of relative weight and obesity. J Chron Dis 25:329-343, 1972

27. Thomas AE, McKay DA, Cutlip MB: A nomograph method for assessing body weight. Am J Clin Nutr 29:302-304, 1976

28. Saltin B, Lindgārde $F$, Houston $M$, et al: Physical training and glucose tolerance in middle-aged men with chemical diabetes. Diabetes 28(Suppl 1): 30-32, 1979

29. Ruderman NB, Ganda OP, Johansen K: The effect of physical training on glucose tolerance and plasma lipids in maturity-onset diabetes. Diabetes 28(Suppl 1):89-92, 1979

30. Björntorp P, DeJounge K, Krotkiewski M, et al: Physical training in human obesity. III. Effects of long-term physical training on body composition. Metabolism 22:1467-1475, 1973

31. Soman VR, Koivisto VA, Deibert D, et al: Increased insulin sensitivity and insulin binding to monocytes after physical training. N Engl J Med 301:1200-1204, 1979

32. Wallberg-Henriksson H, Gunnarsson R, Henriksson J, et al: Increased peripheral insulin sensitivity and muscle mitochondrial enzymes but unchanged blood glucose control in type I diabetics after physical training. Diabetes 31:1044-1050, 1982

33. Rosenthal M, Haskell WL, Solomon R, et al: Demonstration of a relationship between level of physical training and insulinstimulated glucose utilization in normal humans. Diabetes 32:408411,1983

34. Bogardus C, Lillioja S, Mott D, et al: Relationship between obesity and maximal insulin-stimulated glucose uptake in vivo and in vitro in Pima Indianas. I Clin Invest 73:800-805, 1984

35. DeFronzo RA, Tobin JD, Andres R: Glucose clamp technique: A method for quantifying insulin secretion and resistance. Am J Physiol 237(3):E214-223, 1973
36. Greenfield MS, Doberne L, Kraemer F, et al: Assessment of insulin resistance with the insulin suppression test and the euglycemic clamp. Diabetes 30:387-392, 1981

37. Reaven GM, Mejean L, Villaume C, et al: Plasma glucose and insulin response to oral glucose in nonobese subjects and patients with endogenous hypertriglyceridemia. Metabolism 32:447-450, 1983

38. Havel RJ, Kane JP, Balasse EO, et al: Splanchnic metabolism of free fatty acids and production of very low density lipoproteins in normotriglyceridemic and hypertriglyceridemic humans. $\mathbf{J}$ Clin Invest 49:2017-1035, 1970

39. Boberg J, Carlson L, Freyschuss U, et al: Splanchnic secretion rates of plasma triglycerides and total and splanchnic turnover of plasma free fatty acids in men with normo- and hypertriglyceridemia. Eur J Clin Invest 2:454-466, 1972

40. Beil U, Grundy SM, Crouse JR, et al: Triglyceride and cholesterol metabolism in primary hypertriglyceridemia. Arteriosclerosis $2: 44-57,1982$

41. Nikkilä EA: Control of plasma and liver triglyceride kinetics by carbohydrate metabolism and insulin. Adv Lipid Res 7:63-134, 1969

42. Nikkilä EA, Taskinen M-R, Rehunen S, et al: Lipoprotein lipase activity in adipose tissue and skeletal muscle of runners: Relation to serum lipoproteins. Metabolism 27:1661-1671, 1978

43. Williams PT, Wood PD, Haskell WL, et al: The effects of running mileage and duration on plasma lipoprotein levels. JAMA $247: 2674-2679,1982$

44. Wond PD, Haskell WL, Blair SN, et al: Increased exercise level and plasma lipoprotein concentrations: A one-year, randomized, controlled study in sedentary, middle-aged men. Metabolism $32: 31-39,1983$ 